\title{
Physiochemical and Antibacterial Activity Investigation on Noble Schiff Base Cu(II) Complex
}

\author{
Jasmin Ara Shampa ${ }^{1}$, Md. Rakibul Islam ${ }^{1}$, Md. Saddam Hossain ${ }^{1}$, Gagi Tauhidur Rahman ${ }^{2}$, \\ C. M. Zakaria ${ }^{1}$, Md. Kudrat-E-Zahan ${ }^{1, *}$ \\ ${ }^{1}$ Department of Chemistry, University of Rajshahi, Rajshahi, Bangladesh \\ ${ }^{2}$ Department of Material Science \& Engineering, University of Rajshahi, Rajshahi, Bangladesh \\ Email address: \\ inr.shampa@gmail.com (J. A. Shampa), inr.rakib@gmail.com (Md. R. Islam), saddamru4535@gmail.com (Md. S. Hossain), \\ tauhid.mse.ru@gmail.com (G. T. Rahman), cmzakaria@ru.ac.bd (C. M. Zakaria), kudrat.chem@ru.ac.bd (Md. Kudrat-E-Zahan) \\ ${ }^{*}$ Corresponding author
}

\section{To cite this article:}

Jasmin Ara Shampa, Md. Rakibul Islam, Md. Saddam Hossain, Gagi Tauhidur Rahman, C. M. Zakaria, Md. Kudrat-E-Zahan. Physiochemical and Antibacterial Activity Investigation on Noble Schiff Base Cu(II) Complex. American Journal of Heterocyclic Chemistry. Vol. 3, No. 4, 2017, pp. 37-41. doi: 10.11648/j.ajhc.20170304.11

Received: July 11, 2017; Accepted: July 26, 2017; Published: August 28, 2017

\begin{abstract}
Schiff base ligand and its $\mathrm{Cu}(\mathrm{II})$ complex had been synthesized by the condensation reaction of isatin with amino acids (cysteine / glycine / leucine / alanine ). The Structure and spectral properties of ligand and complex were confirmed by UV, FT-IR and some physiochemical measurements. The spectral properties showed that it was a distorted tetrahedral geometry with a tridentate ligand and chloride ion. IR spectral studies show the binding sites of the Schiff base ligand with the metal ion. Molar conductance data and magnetic susceptibility measurements give evidence for monomeric and non-electrolytic nature of the complexes. The Schiff base $\mathrm{Cu}$ (II) complex was subjected to antimicrobial studies screened by employing the Disc Diffusion method. All the synthesized complexes showed strong antibacterial activity.
\end{abstract}

Keywords: Transition Metal Cu(II) Complexes, Schiff Base, Amino Acid, Antimicrobial Studies

\section{Introduction}

Multidentate ligands are extensively used for the preparation of metal complexes with interesting properties [13]. Among these ligands, Schiff bases containing nitrogen and phenolic oxygen donor atoms are of considerable interest due to their potential application in catalysis, medicine and material science [4-7]. Transition metal complexes of these ligands exhibit varying configurations, structural lability and sensitivity to molecular environments. The central metal ions in these complexes act as active sites for pharmacological agent. This feature is employed for modeling active sites in biological systems.

Amino acids and Isatin are important to the pharmaceutical industry, since they have antibacterial and antitubercular action. Schiff bases obtained by the condensation of Isatin and amino acids in presence of potassium hydroxide find application as antituberculosis compounds. They also find application in the biophysical and clinical studies as metal ligand luminescence probes [8]. Recently, few mixed ligand complexes containing heterocyclic amine as secondary ligands and few Schiff base containing complexes have studied in our laboratory [9-11]. Therefore, in view of our interest in synthesis of new Schiff base complexes, which might find application as pharmacological and as luminescence probes, we have synthesized and characterized $\mathrm{Cu}$ (II) metal ion complexes of noble Schiff base formed by the condensation of isatin and amino acids in presence of potassium hydroxide.

\section{Experimental}

Infrared spectra disc were recorded as $\mathrm{KBr}$ with a NICOLET 310, FTIR spectrophotometer, Belgium, from 4000-225 $\mathrm{cm}^{-1}$. Magnetic measurements have been carried out in a Sherwood Scientific magnetic susceptibility balance at room temperature. The measurements of magnetic susceptibilities were made at about constant temperature. The electronic spectra of the ligand and complex in UV-Vis region were obtained in DMSO Solutions using a Shimadzu UV-1200 Spectrophotometer in the range of 200-800 nm. 


\subsection{Synthesis of Schiff Bases}

To a stirring solution of isatin $(0.735 \mathrm{~g}, 0.005$ mole) dissolved in $25 \mathrm{~mL}$ of ethanol, a solution of amino acids (cysteine $0.6058 \mathrm{~g}$, glycine $0.3754 \mathrm{~g}$, leucine $0.6559 \mathrm{~g}$, alanine $0.4455 \mathrm{~g}, 0.005$ mole) dissolved in $10 \mathrm{~mL}$ water was added drop wise and in this mixture, a solution of potassium hydroxide $(0.2805 \mathrm{~g}, 0.005$ mole) dissolved in $10 \mathrm{~mL}$ water was added slowly. This has resulted a dark red solution, which was refluxed for $6 \mathrm{~h}$. The reaction mixture was cooled and kept for evaporation at room temperature leading to isolation of solid product. The product thus formed was filtered washed several times with ethanol and finally with diethyl ether and dried in vacuum over anhydrous $\mathrm{CaCl}_{2}$. The product was found to be soluble in DMF and DMSO. The target Schiff bases were synthesized according to Figures 1-4.

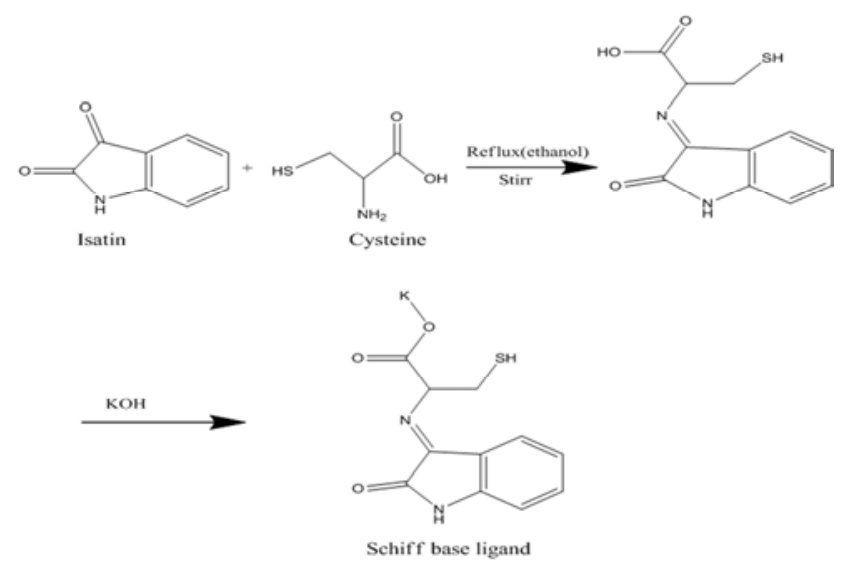

Figure 1. Synthesis of potassium-3-mercapto-2-((2-oxoindolin-3ylidene)amino)propanoate, $\left(\mathrm{C}_{11} \mathrm{H}_{9} \mathrm{SN}_{2} \mathrm{O}_{3}\right)$.

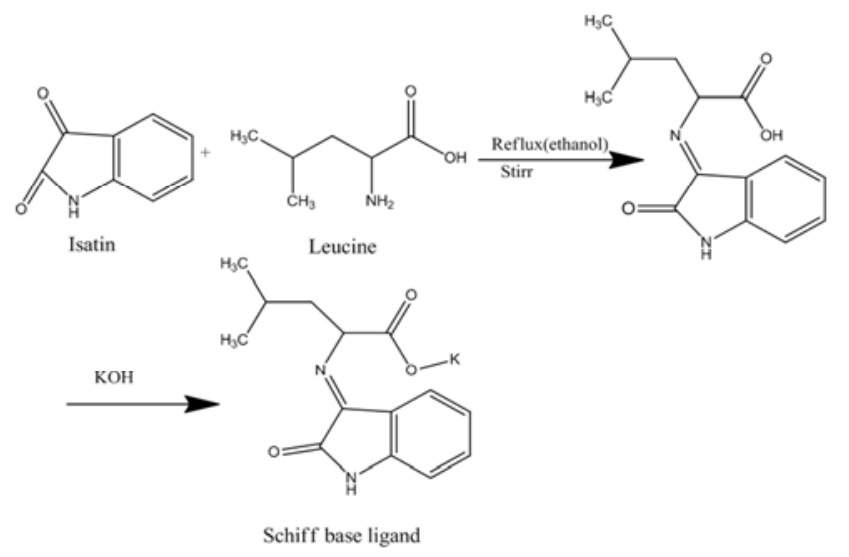

Figure 2. Synthesis of potassium-4-methyl-2-((2-oxoindolin-3-ylidene) amino) pentanoate, $\left(\mathrm{C}_{14} \mathrm{H}_{15} \mathrm{~N}_{2} \mathrm{O}_{3}\right)$.

\subsection{Synthesis of Metal Complexes}

To a stirring solution of isatin $(0.735 \mathrm{~g}, 0.005 \mathrm{~mol})$ dissolved in $25 \mathrm{~mL}$ of ethanol, a solution of amino acids (cysteine $0.6058 \mathrm{~g} /$ glycine $0.3754 \mathrm{~g} /$ leucine $0.6559 \mathrm{~g} /$ alanine $0.4455 \mathrm{~g}, 0.005 \mathrm{~mol}$ ) dissolved in $10 \mathrm{~mL}$ water was added drop wise and in this mixture, a solution of potassium hydroxide $(0.2805 \mathrm{~g}, 0.005 \mathrm{~mol})$ dissolved in $10 \mathrm{~mL}$ water was added slowly. This has resulted a dark red solution and a solution of cupric chloride $(0.8525 \mathrm{~g}, 0.005 \mathrm{~mol})$ dissolved in $10 \mathrm{~mL}$ water was added slowly to this solution. Then dark red color turns to gray color and the mixture was refluxed for 6 hours leading to the isolation of solid product. The complexes thus formed were filtered and washed several times with ethanol to remove any traces of unreacted starting materials and were further washed with diethyl ether and dried in vacuum over anhydrous $\mathrm{CaCl}_{2}$. The complexes were soluble in DMF and DMSO.
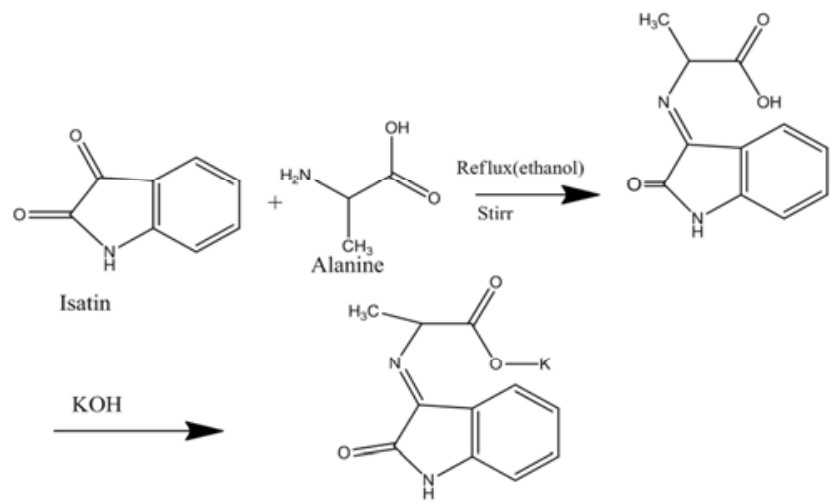

Schiff base ligand

Figure 3. Synthesis of potassium-2-((2-oxoindolin-3-ylidene) amino) propanoate, $\left(\mathrm{C}_{11} \mathrm{H}_{9} \mathrm{~N}_{2} \mathrm{O}_{3}\right)$.

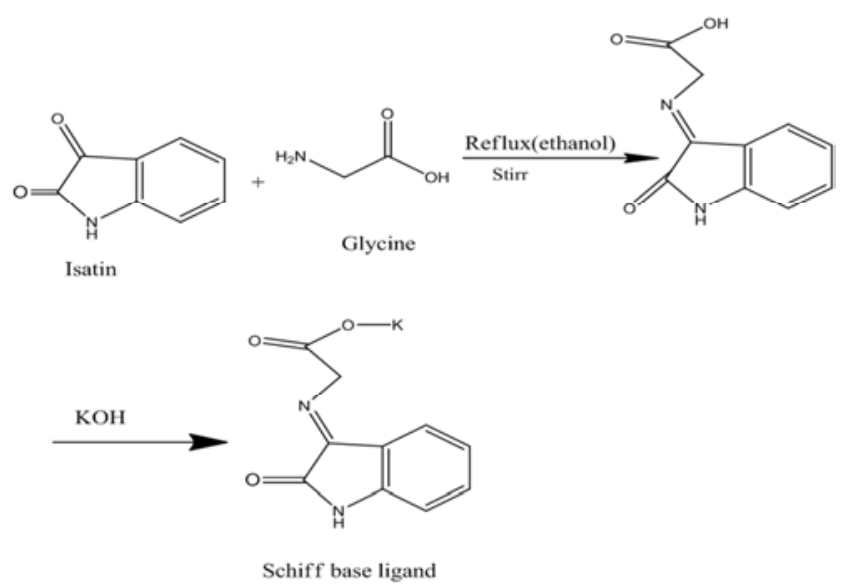

Figure 4. Synthesis of potassium-2-((2-oxoindolin-3-ylidene) amino) acetate, $\left(\mathrm{C}_{10} \mathrm{H}_{7} \mathrm{~N}_{2} \mathrm{O}_{3}\right)$.

\section{Characterization}

\subsection{Physical Measurement}

The melting point of the complexes prepared for this study is given in Table 1. All the complexes are non-electrolyte. The observed values of effective magnetic moment $\left(\mu_{\text {eff }}\right)$ of the complexes at room temperature are given in Table 1 . From the above data it is showed that all the complexes are paramagnetic in nature [11, 12].

\subsection{IR Spectral Analysis}

The IR spectrum of the isatin exhibited characteristic 
bands at $1732 \mathrm{~cm}^{-1}, 3414 \mathrm{~cm}^{-1}$ and $3191 \mathrm{~cm}^{-1}$ assigned to $v$ $(\mathrm{C}=\mathrm{O}), v(\mathrm{~N}-\mathrm{H})$ and $v(\mathrm{C}-\mathrm{H})$. The complexes exhibited characteristic bands at 1724-1715 $\mathrm{cm}^{-1}, 1618-1608 \mathrm{~cm}^{-1}$, $3415-3353 \mathrm{~cm}^{-1}, 750-740 \mathrm{~cm}^{-1}, 480-470 \mathrm{~cm}^{-1}, 440 \mathrm{~cm}^{-1}$ assigned to $v(\mathrm{C}=\mathrm{O}), v(\mathrm{C}=\mathrm{N}), v(\mathrm{~N}-\mathrm{H}), v(\mathrm{Cu}-\mathrm{Cl}), v(\mathrm{Cu}-\mathrm{O})$ and $v(\mathrm{Cu}-\mathrm{N})$ [13-15]. The characteristics band indicated that ligand coordinated to the metal through $\mathrm{N}, \mathrm{O}$.

Table 1. The physiochemical properties of the metal complexes.

\begin{tabular}{lllll}
\hline Complexes & Color & Melting point $(+/-5)^{\circ} \mathbf{C}$ & $\mu_{\text {eff }}$ in B. M. & Molar conductanceScm $^{2}$ mot $^{\boldsymbol{I}}$ \\
\hline$\left[\mathrm{Cu}\left(\mathrm{C}_{14} \mathrm{H}_{15} \mathrm{~N}_{2} \mathrm{O}_{3}\right) \mathrm{Cl}\right]$ & Pink & 162 & 1.02 & 8.00 \\
{$\left[\mathrm{Cu}\left(\mathrm{C}_{10} \mathrm{H}_{7} \mathrm{~N}_{2} \mathrm{O}_{3}\right) \mathrm{Cl}\right]$} & Brown & 243 & 1.00 & 9.00 \\
{$\left[\mathrm{Cu}\left(\mathrm{C}_{11} \mathrm{H}_{9} \mathrm{~N}_{2} \mathrm{O}_{3}\right) \mathrm{Cl}\right]$} & Gray & 241 & 1.00 & 6.00 \\
{$\left[\mathrm{Cu}\left(\mathrm{C}_{11} \mathrm{H}_{9} \mathrm{SN}_{2} \mathrm{O}_{3}\right) \mathrm{Cl}\right]$} & Yellowish brown & 160 & 1.00 & 10.00 \\
$\mathrm{C}_{11} \mathrm{H}_{9} \mathrm{KN}_{2} \mathrm{O}_{3} \mathrm{~S}$ & Reddish brown & 90 & -- & 15.00 \\
$\mathrm{C}_{14} \mathrm{H}_{15} \mathrm{KN}_{2} \mathrm{O}_{3}$ & Gray & 115 & -- & 6.00 \\
\hline
\end{tabular}

\subsection{Characterizations by UV-Visible Spectra}

Because of the relatively low symmetry of the environments in which the $\mathrm{Cu}^{2+}$ ion is characteristically found, detailed interpretations of the spectra and magnetic properties are somewhat complicated, even though one is dealing with the equivalent of a one - electron case [16]. Virtually all complexes and compounds are blue or green. Exceptions are generally caused by strong UV bands charge transfer bands - tailing off into the blue end of the visible spectrum, thus causing the substances to appear red or brown [17]. The observed $\lambda_{\max }$ values are used to predict the geometry around the central metal ion in the complex. The electronic spectra of Ligand show similar absorption bands and obtain at $290 \mathrm{~nm}$. These bands shows the presence of $\mathrm{n} \rightarrow \mathrm{n}^{*}$ and $\pi \rightarrow \pi^{*}$ transitions of their azomethines chromophore group and aromatic ring. But in the Spectra of complexes, slightly shifts are observed in the position and intensity of these bands as com- pare to that of ligand which might be due to the coordination of metal with the ligand. All the synthesized complexes showed d-d transitions at $410 \mathrm{~nm}$ which is due to ${ }^{2} \mathrm{~B}_{1 \mathrm{~g}} \rightarrow{ }^{2} \mathrm{~A}_{1 \mathrm{~g}}$ transition indicated the distorted tetrahedral structure [18].

Table 2. Antibacterial activities of the complexes and Streptomycin.

\begin{tabular}{|c|c|c|c|}
\hline \multirow{2}{*}{ Bacterials strains } & \multicolumn{3}{|c|}{ Zone of inhibition, diameter in $\mathrm{mm}$} \\
\hline & {$\left[\mathrm{Cu}\left(\mathrm{C}_{10} \mathrm{H}_{7} \mathrm{~N}_{2} \mathrm{O}_{3}\right) \mathrm{Cl}\right](10 \mu \mathrm{g} / \mathrm{disc})$} & {$\left[\mathrm{Cu}\left(\mathrm{C}_{14} \mathrm{H}_{15} \mathrm{~N}_{2} \mathrm{O}_{3}\right) \mathrm{Cl}\right](10 \mu \mathrm{g} / \mathrm{disc})$} & Streptomycin $(10 \mu \mathrm{g} / \mathrm{disc})$ \\
\hline Bacillus subtilis & 20 & 17 & 27 \\
\hline Staphylococcus aureus & 27 & 28 & 34 \\
\hline Escherichia coli & 12 & 14 & 21 \\
\hline Proteus vulgaris & 22 & 23 & 28 \\
\hline
\end{tabular}

\section{Antibacterial Activity}

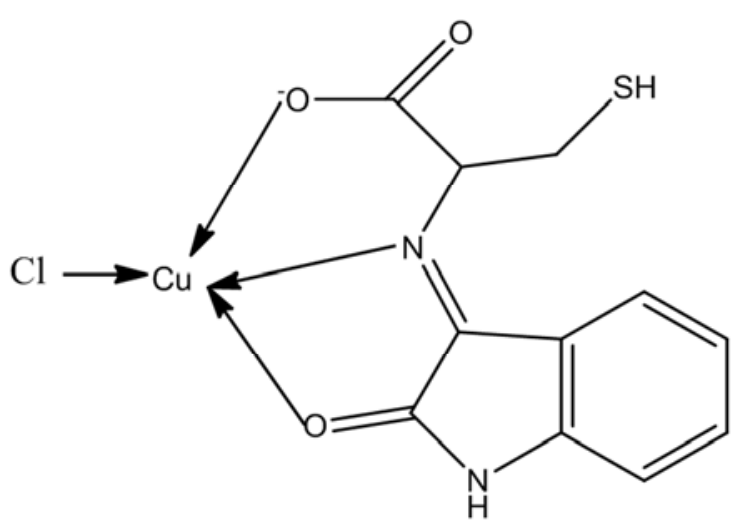

Figure 5. Monocopper(II) mono ((3-mercapto-2-((2-oxoindolin-3-ylidene) amino) propanoate) monochloride.

Any chemical or biological agent that either destroys or inhibits the growth of microorganisms is called antimicrobial agent. The susceptibility of microorganism to antimicrobial agent can be determined in vitro by a number of methods. The disc diffusion technique [19] is widely acceptable for preliminary investigations of materials which are suspected to possess antimicrobial properties. Diffusion procedure, as normally used in essentially a qualitative test, which allocates organism of the susceptible, intermediate (moderately susceptible) or resistant categories. The antibacterial activity of the test complexes were determined by using the dose of $10 \mu \mathrm{g} /$ disc. The results of antibacterial activity measured in terms of zone of inhibition is shown in Table-2. The complexes showed strong sensitivity against the following number of both gram positive and gram negative bacteria and the results were compared with antibiotic disc of Streptomycin. The maximum zone of inhibition $28 \mathrm{~mm}$ was obtained against Staphylococcus aureus by $\left[\mathrm{Cu}\left(\mathrm{C}_{14} \mathrm{H}_{15} \mathrm{~N}_{2} \mathrm{O}_{3}\right) \mathrm{Cl}\right]$.

\section{Conclusion}

Magnetic susceptibility data indicated that all the complexes are paramagnetic in nature. Conductivity measurement indicated that all the complexes are nonelectrolyte in nature. IR spectral data showed the ligand coordinate with metal complexes through $\mathrm{O}$ and $\mathrm{N}$ atoms. $\mathrm{UV}$-Vis data showed the presence of $\mathrm{d}-\mathrm{d}$ transition and paramagnetic nature nature of the complexes. There are two possibilities $\mathrm{Cu}(\mathrm{I}) / \mathrm{Cu}(\mathrm{II})$ state. Where, the $\mathrm{Cu}(\mathrm{II})$ oxidation 
state is more stable than $\mathrm{Cu}(\mathrm{I})$ for complexes with nitrogen or oxygen electron donating ligands because of the CFSE. The $\mathrm{d}^{9}$ of $\mathrm{Cu}(\mathrm{II})$ configuration has more CFSE than $\mathrm{d}^{10}$ of $\mathrm{Cu}(\mathrm{I})$ which is zero. Keeping this in mind and judging from all the experimental data it was concluded that the geometry around $\mathrm{Cu}$ (II) ions in the respective complexes might be distorted tetrahedral and structures of complexes have been proposed as shown in figures 5-8. All the complexes showed strong antibacterial activity.



Figure 6. Monocopper(II) mono ((4-methyl-2-((2-oxoindolin-3-ylidene) amino) pentanoate) monochloride.

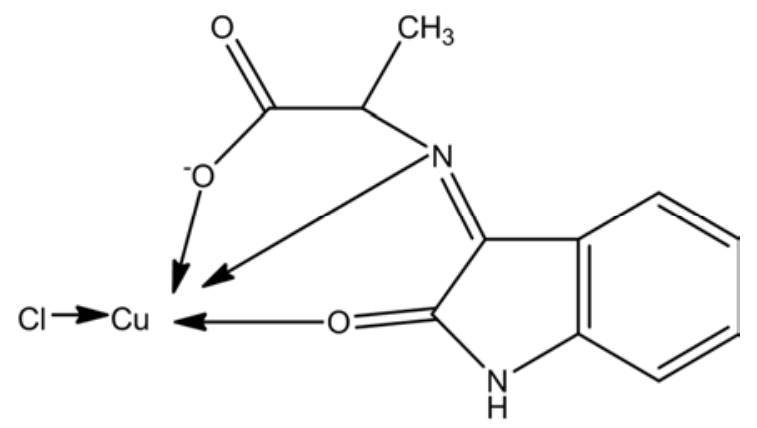

Figure 7. Monocopper(II) mono ((-2-((2-oxoindolin-3-ylidene) amino) propanoate) monochloride.

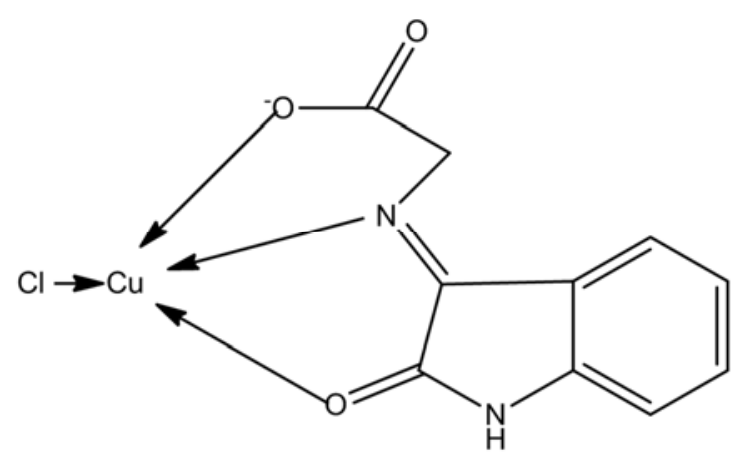

Figure 8. Monocopper(II) mono ((2-((2-oxoindolin-3-ylidene) amino) acetate) monochloride.

\section{Acknowledgements}

The authors would like to thank the management of Department of Pharmacy, Rajshahi University for providing the lab facilities.

\section{Conflict of Interest}

The authors have no conflict of interest to publish the article.

\section{References}

[1] Kirza, L. Ababel, N. Rau, N. Stanica. (2013) Synthesis and structural studies of complexes of $\mathrm{Cu}, \mathrm{Co}, \mathrm{Ni}$ and $\mathrm{Zn}$ with isonicotinic acid hydrazide and isonicotinic acid (1naphthylmethylene) hydrazide J. Serb. Chem. Soc., 75 (2): 229-242.

[2] L. Mitu, A. Kriza. (2007) Synthesis and Characterization of Complexes of $\mathrm{Mn}(\mathrm{II}), \mathrm{Co}(\mathrm{II}), \mathrm{Ni}(\mathrm{II})$ and $\mathrm{Cu}(\mathrm{II})$ with an Aroylhydrazone Ligand. Asian J. Chem. 19 (1): 658-664.

[3] Saud I. Al-Resayesa, Mohammad Shakirb, AmbreenAbbasib, Kr. Mohammad Yusuf Aminc, Abdul Lateefc. (2007) Synthesis, spectroscopic, characterization and biological activities of $\mathrm{N}_{4} \mathrm{O}_{2}$ Schiff base ligand and its metal complexes of $\mathrm{Co}(\mathrm{II}), \mathrm{Ni}(\mathrm{II}), \mathrm{Cu}(\mathrm{II})$ and $\mathrm{Zn}(\mathrm{II})$. SpectrochimicaActa Part A. 93: 86-94.

[4] K. D. Karlin, Z. Tyeklar, Ken. D. Karlin. Bioinorganic Chemistry of Copper. Chapman \&Hall: NewYork. 1993.

[5] V. Arun, N. Sridevi, P. P. Robinson, S. Manju, K. K. M. Yusuff. (2009) Ni(II) and Ru(II) Schiff base complexes as catalysts for the reduction of benzene. J. Mol. Catal. Chem., 304 (1): 191-198.

[6] K. C. Gupta, A. K. Sutar. (2009) Catalytic activities of Schiff base transition metal complexes. Coord. Chem. Rev. 252 (1214) $0: 1420-1450$.

[7] R. I. Kureshy, N. H. Khan, S. H. R. Abdi, S. T. Patel, P. Iyer. (1999) Synthesis, physico-chemical studies and solventdependent enantioselective epoxidation of 1, 2dihydronaphthalene catalysed by chiral Ruthenium (II) Schiff base complexes. I. J. Mol. Cat. A Chem., 150 (1): 63-173.

[8] Aly M. A. Hassaan. (1999) Nickel (II) chelates of Schiff bases derived from isatin and chromone with amino acids and substituted hydrazines. Transition Metal Chemistry, 15 (4): 283-285.

[9] Gagi Tauhidur Rahman, A. B. M. Nazmul Islam, M. M. Haque, Md. Kudrat-E-Zahan, (2015) Investigation on Antimicrobial Activity of Newly Synthesized Mixed Ligand Ni(II) Ion Complexes. Int. J. Mat. Chem and Phys. 1 (2): 207-211.

[10] Md. Kudrat-E-Zahan, Md. Abdul Alim Al-Bari, Md. Abul Bashar, Laila ArjumanBanu, M. M. Haque and M. Saidul Islam. (2015) Synthesis, Characterization and Biological Activity of Fe(III) Complexes with tartaric acid/succinic acid and heterocyclic amines. Int. J. Mat. Chem and Phys, 1 (1): 82-85.

[11] M. M. Haque, Md. Kudrat-E-Zahan, Laila ArjumanBanu, Md. Shariful Islam and M. S. Islam. Synthesis and Characterization with Antineoplastic, Bio-Chemical, Cytotoxic and Antimicrobial studies of Schiff Base $\mathrm{Cu}$ (II) ion Complexes. Bioinorganic Chemistry and Applications. Volume 2015, Article ID 923087, 7 pages. http://dx.doi.org/10.1155/2015/923087 
[12] Md. Saddam hossain, Md. Ashraful Islam, C. M. Zakaria, Md. Kudrat-E-Zahan. (2016) Synthesis, Spectral and Thermal Characterization with Antimicrobial Studies on Mn(II), Fe(II), $\mathrm{Co}(\mathrm{II})$ and $\mathrm{Sn}(\mathrm{II})$ Complexes of Tridentate N, O Coordinating Novel Schiff Base Ligand. J. Chem. Bio, Phy. Sci. Sec. A. 6 (1): 041-051.

[13] Md. Saddam Hossain, C. M. Zakaria, M. M. Haque, and Md. Kudrat-E- Zahan, (2016) Spectral and Thermal Characterization with Antimicrobial Activity on $\mathrm{Cr}$ (III) and Sn(II) Complexes containing N, O Donor Novel Schiff Base Ligand. International Journal of Chemical Studie, 4 (6): 08-11.

[14] Md. Saddam Hossain, Shudeepta Sarker, A. S. M. Elias Shaheed, Md. Mamun Hossain, Abdul Alim-Al-Bari, Md. Rabiul Karim, C. M. Zakaria, Md. Kudrat-E-Zahan. (2017) Thermal and Spectral Characterization of $\mathrm{Cr}(\mathrm{III}), \mathrm{Co}(\mathrm{II})$ and Cd(II) Metal Complexes Containing Bis-Imine Novel Schiff Base Ligand Towards Potential Biological Application. Chemical and Biomolecular Engineering. 2 (1): 41-50.

[15] Francis A. Carey. Organic chemistry. Seventh edition. The Mc Graw Hill companies, 2008: 539.
[16] F. A. Cotton and G. Wilkinson. Advanced inorganic chemistry, fifth edition, Awiley-interscience publication. 1198: 768.

[17] P. Deivanayagam, R. Pa. Bhoopathy, S. Thanikaikarasan. (2014) Synthesis, characterization, antimicrobial, analgesic and CNS studies of Schiff base $\mathrm{Cu}(\mathrm{II})$ complex derived from 4-choro-o-phenylene Diamine. Int. J. Adv. Chem. 2 (2): 166170 .

[18] Md. Shiraj-U-Ddaula, Md. Anarul Islam, Shejuty aktar, Md. Khairul Islam, Md. Abdul Alim Al-Bari, Md. Masuqul Haque and Md. Kudrat-E-Zahan. Synthesis, Characterization and Antimicrobial Activity of $\mathrm{Cd}(\mathrm{II}), \mathrm{Ni}(\mathrm{II}), \mathrm{Co}(\mathrm{II})$ and $\mathrm{Zr}(\mathrm{IV})$ Metal Complexes of Schiff Base Ligand Derived from Diethylenetriamine and Isatin. Asian J. Research Chem. 7 (7): July 2014.

[19] Bauer, A. W., D. M. Perry, and W. M. M. Kirby. (1999) Single disc antibiotic sensitivity testing of Staphylococci. A. M. A. Arch. Intern. Med. 104: 208-216. 